\title{
Terapia
de família
}

Heloisa Szymanski Ribeiro Gomes

Professora do Depto. de Psicologia da

Universidade Católica de Santos - SP

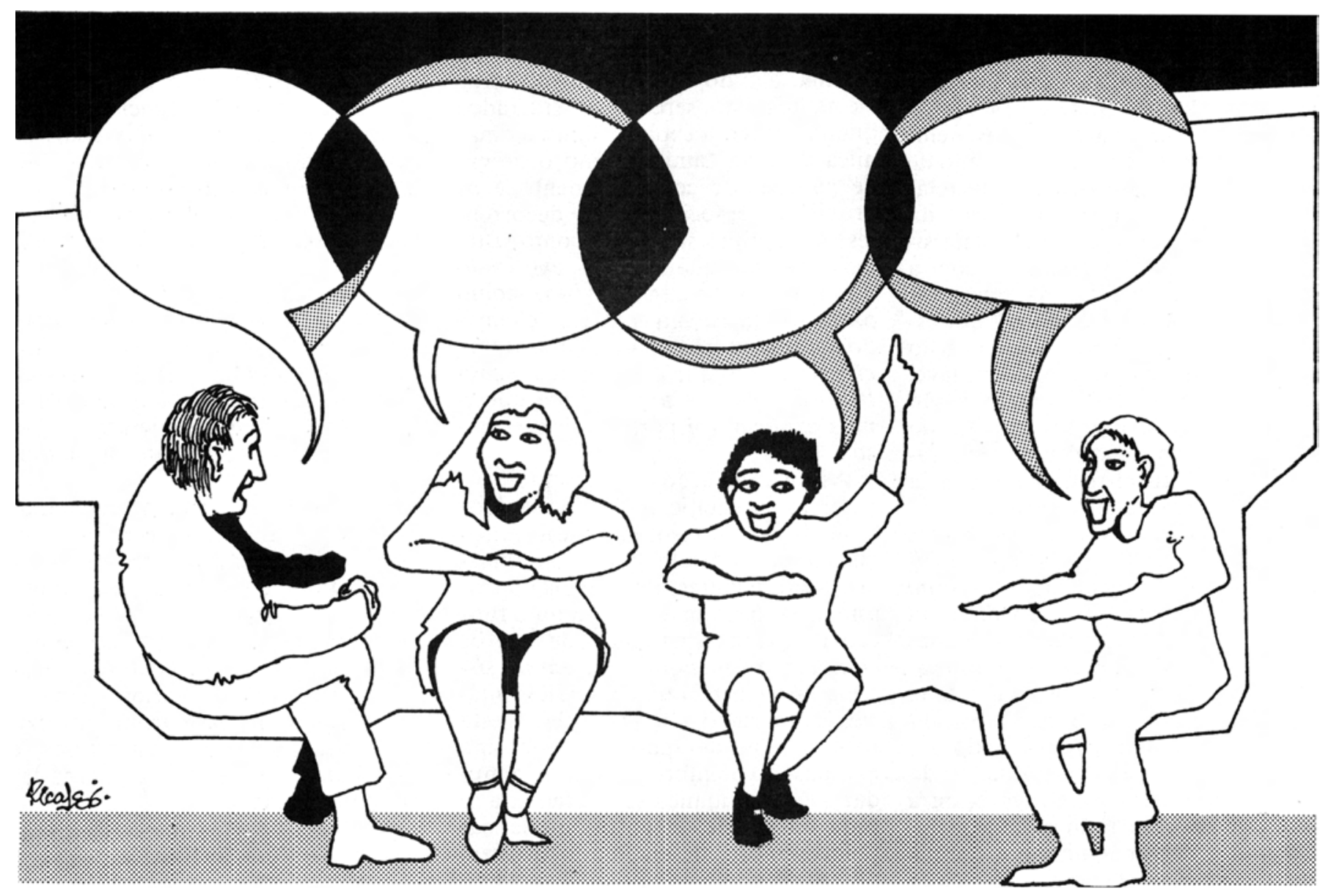

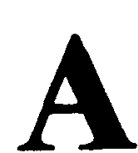

terapia de famílias é uma nova forma de trabalho em nosso meio, embora já adotada há mais ou menos 30 anos na América do Norte e Europa. Ela é nova como proposta de atenderse ao mesmo tempo pais, filhos e até avós e tios, e, se necessário, até mesmo grupos de vizinhança e escola (Speck e Attneave, 1976). A razão de se incluir toda a familia no tratamento de problemas de ajustamento baseia-se no fato de que o que ocorre num indivíduo que vive numa família não decorre apenas de condições internas a ele, mas também de um intenso intercâmbio com o contexto mais amplo no qual está inserido. Ele não só recebe o impacto desse ambiente como atua sobre ele, influenciando-o. Nesse enfoque, o terreno da patologia, como diz Minuchin (1982), é a família.

Num grupo familiar disfuncional os modos de interação entre seus membros vão-se cristalizando, quer na forma de distanciamento, ou de excessiva interferência na vida uns dos outros, formando alianças entre alguns membros, deixando outros periféricos, ou transformando outros em bodes expiatórios (geralmente a criança). Sintomas como baixo rendimento na escola, agressividade, depressão são vistos como próprios da pessoa sintomática, e esta é vista co- 
mo um caso isolado. Nesse pano-defundo as famílias enfermas fracassam progressivamente no cumprimento de suas funções familiares essenciais, (Carneiro, T., 1983).

Do ponto de vista da comunicação, a família sintomática perde-se em críticas, acusações, silêncios, duplas mensagens: há muita dificuldade em colocar-se no lugar do outro e rigidez em tentar novas formas de resolver problemas. Do ponto de vista de estrutura, os papéis são mal definidos, com filhos desempenhando papéis paternos e pais formando alianças com filhos, excluindo o outro membro do casal. Do ponto de vista dinâmico, há, em muitos casos, dificuldade em assumir a função de pais, com suas responsabilidades e limites, bem como dificuldade em estabelecer objetivos familiares e organizar-se para atingi-los. (Weitzman, 1985).

Assim, o sintoma de um dos membros da família vem acompanhado de disfunçōes em outras áreas de relações e envolem outros membros da família. Tendo isto em mente, na situação terapêutica trabalha-se com a família real, presente, na busca de desvendar aspectos relacionais que estão emperrando uma comunicação efetiva e o desenvolvimento saudável de seus membros. Os sintomas são vistos como tendo tanto uma função individual como social no grupo familiar e constituem-se numa denúncia de que algo vai mal nesse grupo.

$\mathrm{Na}$ medida em que os terapeutas começaram a lidar com a familia como unidade terapêutica, afloraram outros aspectos inerentes à vida familiar, aspectos causadores de sintomas e que tinham sido negligenciados (Satir, 1980). O trabalho da terapeuta é, então, o de buscar esses aspectos causadores de sintomas, focalizando outras relações dentro da familia, tendo em vista mudanças que favoreçam a família como um todo e cada membro em particular. Quando a família passa a experimentar novos modos de se relacionar, os sintomas tendem a desaparecer. Este trabalho não exclui a possibilidade de encaminhamento de um membro particular para um trabalho individualizado, quando se constata que é necessário um aprofundamento, bem como uma mudança ao nível do indivíduo.

No decorrer do tempo, foram-se desenvolvendo vários enfoques, ou escolas de terapia de famílias, que, de forma geral, tiveram duas grandes raizes: a teoria dos sistemas, informação e cibernética e teorias psicodinâ- micas. No enfoque sistêmico, Gregory Bateson deu uma grande contribuição para a compreensão dos processos de comunicação. Com Bateson, e o grupo que se formou para estudo de famílias de esquizofrênicos (Don J. Jackson, Jay Haley e John H. Weakland) tem início o enfoque sistêmico no estudo de famílias, que hoje se apresenta com nuanças diferentes, segundo seus vários autores. A idéia central, entretanto, permanece no abandono da explicação linear, causal, histórica do distúrbio mental e na focalização do interrelacional, onde a manipulação da informação e a natureza das relações constituem os elementos explicativos básicos.

Nessa visão teórica, a forma de se comunicar, e o impacto do comportamento de um em relação a outro na família, agindo e retroagindo, são os elementos a serem considerados quando se tenta explicar tanto a dinâmica de uma família como o desvio de padrões de comportamento e os problemas emocionais daí decorrentes. As familias são vistas como sistemas vivos nos quais uma ... expressão ou ação particular (é vista) como parte do subsistema ecológico chamado contexto e não como o produto ou efeito daquilo que permanece no contexto depois que a parte que queremos explicar foi cortada dele (Bateson, 1978).

Assim, cada ação ereação muda a natureza, o campo onde elas se dão. O significado do sintoma, nesse enfoque, muda radicalmente. Comportamentos desviantes, irracionais ou sintomáticos passam a servir a uma função no grupo no sentido de que os comportamentos que ocorrem no sistema familiar têm uma complementariedade geral (Dell, p. 2141). Desta forma, para desaparecer o sintoma não basta o membro sintomático mudar - sua mudança só se efetivará se toda uma série de outras mudanças (nem sempre desejadas) ocorrerem dentro do sistema familiar. Essas mudanças não são desejadas porque implicam mudanças nos vários subsistemas da família - casal, pais, grupo fraterno, avós - e o sistema familiar apresenta uma tendência a um equilíbrio homeostático, onde tudo é feito para que as coisas permaneçam como estão. Exemplificando (e simplificando): muitas vezes o sintoma da criança (medo, p. ex.) pode desaparecer, se o casal mudar a forma de se relacionar entre si (buscando uma aproximação, p. ex.). Como nem sempre o casal está disposto a isso, o sintoma do filho cumpre a função de ao mesmo tempo manter os pais unidos na preocupação com ele,e afastados de uma relação mais próxima entre si. Certamente esse processo não ocorre de forma voluntária, por parte dos pais e do filho, mas acaba se cristalizando numa forma de relacionamento que resiste à tentativa de mudanças.

Do ponto de vista da teoria dos sistemas, desenvolveram-se modelos teóricos e práticas terapêuticas que podem ser classificadas de várias maneiras, (Hoffman, L'Abbate et alii, Madanes, Sluzki).

Há aqueles autores que enfatizam os aspectos estruturais do sistema familiar: limite (i. e., regras de participação) e hierarquia (i. e., regras de poder), (L'Abbate, Frly, Wagner). A estrutura familiar é o conjunto invisivel de exigências funcionais que organiza as maneiras pelas quais os membros da família interagem. Minuchin foi quem propôs esse enfoque estrutural e desenvolveu sua teoria, através da análise dos padrões transacionais que se desenvolvem entre os vários subsistemas da família: o parental, o fraternal, o conjugal. Para ele, o comportamento sintomáticu tem a função de manter as regras de interação que controlam o estabelecimento de fronteiras e hierarquias, e, consequientemente, manter a patologia da família.

$O$ objetivo da terapia, nesse modelo, é o de: a) restabelecer a possibilidade de negociação entre os membros da família quanto ao uso do poder, evitando alianças transgeneracionais (pai com filho, mãe com filho, avó com neto) e b) reorganizar as fronteiras entre os vários subsistemas, apontando para fronteiras inadequadamente rigidas, ou difusas, e trabalhando no sentido de torná-las mais adequadas.

Outro modelo, também no enfoque sistêmico, é o chamado estratégicoum modelo mais voltado para o processo do que para a estrutura da família. Propõe a existência de regras familiares poderosas e controladoras do comportamento dos membros da família, no sentido de evitar a mudança. A intervenção terapêutica se dá através de estratégias que visam quebrar aquelas regras, via prescrição do comportamento sintomático, ou não. A prescrição do sintoma tem sua base teórica na teoria matemática dos grupos e na teoria dos Tipos Lógicos (Watzlawick, Beavim, Jackson, 
1981). Paul Watzlawick, Jay Haley, J. Weakland e R. Fisch são figuras proeminentes na terapia estratégica.

Com muitos pontos em comum com a escola estratégica, desenvolveu-se a escola sistêmica,com - Grupo de Milão: Mara Selvini Palazzoli, Giuliana Prata, Luigi Boscolo, Gianfranco Cecchin. Para esses autores há a necessidade de um reenquadramento da situação, dando uma conotação positiva ao sintoma, prescrevendo-o. Assim, ao nível expresso (verbal) há uma diretiva no sentido de não mudança, mas ao nível não verbal há a proposta de mudança - que é a finalidade da terapia. Tratase de uma proposta terapêutica que, para ser dominada, exige trabalho em equipe e um bom período de treinamento específico, como, evidentemente, o exige qualquer outra técnica de trabalho terapêutico.

Também numa perspectiva sistêmica alguns autores (Speck, Attneave) desenvolveram o que Hoffman chama de modelo ecológico, no qual o trabalho terapêutico com famílias vai além da família nuclear, incluindo o grupo de vizinhança e família extensa (família de origem dos pais). A sistematização desse modelo foi o resultado do trabalho em saúde mental com comunidades economicamente carentes, que necessitavam de profissionais de saúde com uma visão holística do problema de saúde mental. Esse modelo ecológico de tratamento de situações de crise exige a combinação de fatores biológicos, psicológicos, sociais e ambientais.

Além das escolas que se desenvolveram a partir do paradigma sistêmico, há aquelas, chamadas psicodinâmicas, que se desenvolveram a partir do trabalho de terapeutas que, embora não estivessem necessariamente associados à prática psicanalista, adotaram uma forma de procedimentos e interpretaçõesque vão ao encontro de conceitos psicanalíticos. Teóricos psicodinâmicos de orientação kleiniana, por exemplo, vêem a dinâmica da organização familiar como expressão do entrelaçamento destas várias relações objetais relacionadas (Meyer), numa visão de família muito diferente dos sistêmicos que vimos acima.

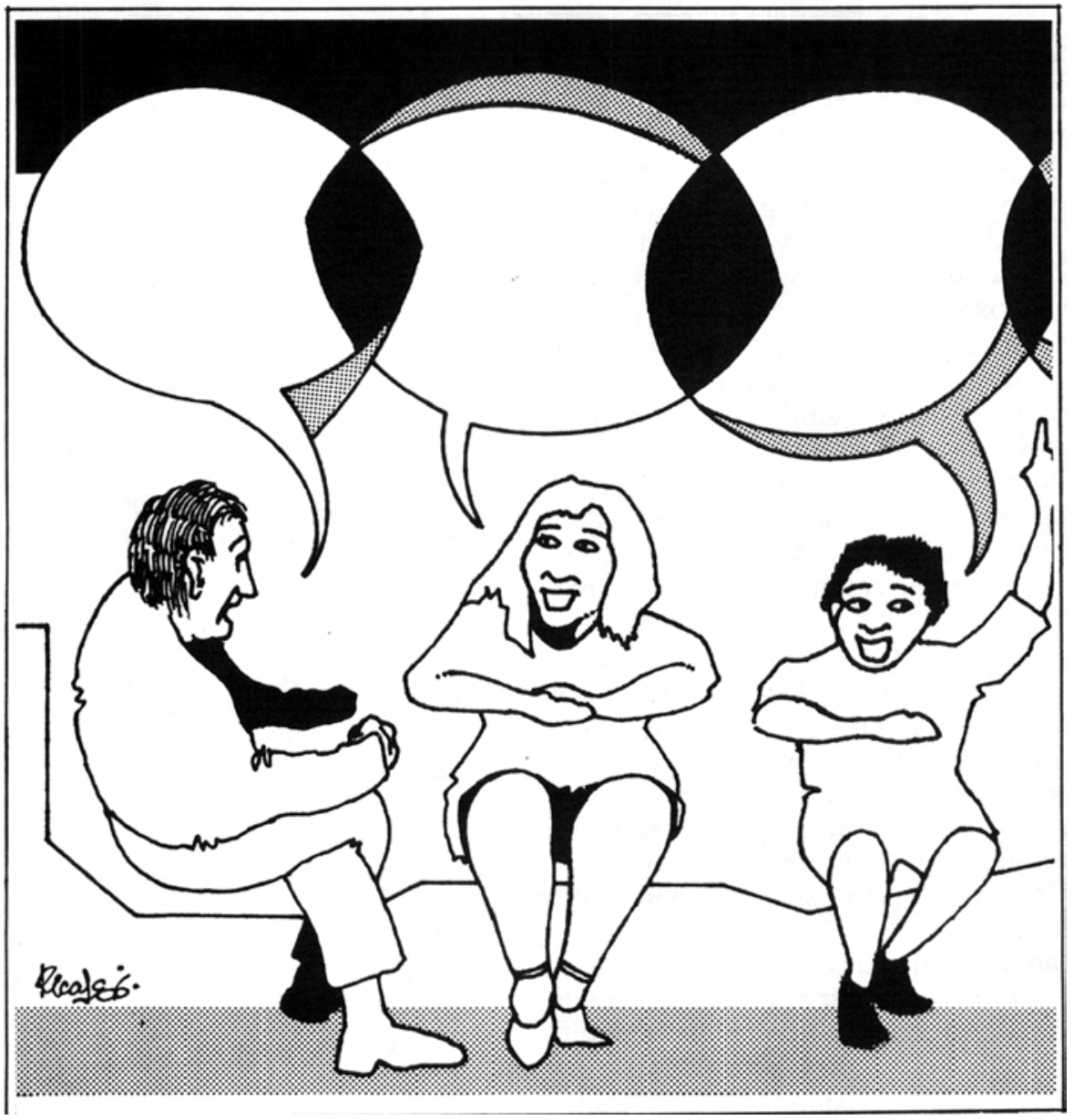

Diferem destes também quanto aos objetivos a alcançar, pois, em vez de trabalhar no sentido de promover alterações imediatas no contexto, onde surge o problema,visam ao crescimento individual dos membros da família.

$O$ terapeuta, nesse enfoque, trabalha com memórias, sentimentos e emoções do passado; não são dadas diretivas e o processo terapêutico é demorado. $O$ objetivo terapêutico é o atingimento de um self individuado. Hoffman sintetiza esse enfoque com a seguinte proposição: Os terapeutas com maior orientação psicodinâmica acreditam que precisamos atingir fatores históricos ou causais para aliviar um sintoma. As versões dos conceitos psicanalíticos de insight, catarse e abreação aplicadas à terapia de famílias parecem ser as maiores avenidas para mudança, e o resultado desejado é uma objetividade madura, como numa terapia freudiana (Hoffman, p. 243). Entre os maiores representantes dessa escola estão Murrey Bowen, Ivan BoszormenyiNagy, Lyman Wynne.

Atualmente, estão se desenvolvendo modelos de trabalho com famílias baseados em teorias existencialistas, humanistas, fenomenológicas e de construção de realidade (L'Abbate et alii, Sluzki).Estas propõem que cada um de nós carrega também "estruturas de crenças que não só organizam a realidade com tal, mas, organizam nosso comportamento na base de suposições, algumas claramente cristalizadas em ideologias, algumas em convicções e muitas de atribuições, que fundem percepçòes e préconceitos em assim é que as coisas devem ser. (Sluzki).

A atuação do terapeuta nesse enfoque visa à reformulação desses modos de interpretação cristalizados, apresentando outras possibilidades interpretativas, de forma que tanto o passado como o presente podem ser reformulados. Isto trará como consequieencia novas modalidades de atuação entre os membros da família.

Numa perspectiva existencialista, o ponto de partida é o da importância da busca de significado para a vida de relação com outro, no desenvolvimento do ser si-mesmo, na responsabilidade de cada um no modelar seu destino, na atentividade aos dados da experiência (sensações, emoções, per- 
cepções e reações). No nível terapêutico não se trata de remover problemas, mas analisá-los em termos da relação do indivíduo com outros no mundo, tendo em vista a busca de possibilidades alternativas de vivercom. Essa reestruturação de valores nos níveis familiar e social coloca problemas existenciais que deverão ser analisados e compreendidos no contexto da vida familiar. Do ponto de vista terapêutico, parte-se nessa perspectiva de um pressuposto oposto ao das teorias sistêmicas: o alívio do sintoma vem como conseqüência de mudanças na experiência interna. Difere das psicodinâmicas no fato de focalizar mais o presente do que o passado, embora às vezes seja necessário reelaborar o passado, em vista do futuro.

Finalmente, há alguns autores que não se localizam especificamente em nenhuma escola de terapia, em virtude de sua excepcional criatividade na condução de seu trabalho terapêutico: Virginia Satir, Nathan Ackermann e Carl Whitaker. (cf. Hoffman).

A partir desse breve apanhado aparecem alguns referenciais para descrever famílias, interpretá-las e propor-lhes tratamento. A escolha de um deles depende, muitas vezes, de fatores fortuitos, outras, de crenças já estabelecidas e também de fatores de personalidade da (do) terapeuta. Os proponentes de cada escola apresentam-na como a escola, $e$ isso talvez seja necessário para que seus elementos indentificadores evidenciem-se.

Quanto à formação da (do) terapeuta, há a possibilidade de especialização em uma linha específica ou o conhecimento de várias. A primeira dá a segurança de estar aplicando uma forma de atuação testada e consagrada. Porém, corre o risco de ver todos os problemas de família numa única perspectiva. A segunda possibilidade - que prevê um treinamento eclético - só é possivel quando o (a) terapeuta aprofunda sua formação tanto prática como teórica em vários enfoques terapêuticos, a fim de evitar a aplicação insistente de uma abordagem que pode ser inadequada para uma familia. Por aprofundamente entenda-se o conhecimento da consistência interna de cada escola de terapia estudada e da justificativa teórica de suas formas de ação. Caso esse cuidado não seja tomado, há o risco de superficialidade.
Por se constituir num campo ainda em formação, não conta com grande número de profissionais especializados e carece de mais cursos de formação e aprofundamento, no nosso meio. Os psicólogos que desejam um aprofundamento maior na área precisam arcar com enormes despesas de locomoção para o exterior, para assistirem a cursos caríssimos, ministrados por especialistas americanos e europeus. Ou então, trazê-los para cá, desembolsando grandes quantias.

Deve-se levar em conta o fato de que o trabalho com familias, como nas demais especializações, requer um cuidadoso treinamento do profissional. Este, na terapia de familias, trabalhará com pessoas de diferentes faixas etárias, que constituem um grupo social numa intrincada dinâmica, da qual o (a) terapeuta passa a fazer parte. Alguns autores chegam mesmo a sugerir que profissionais amadurecidos que tenham se casado e tenham filhos, serão mais facilmente treinados... (Minuchin). O treinamento, além da parte teórica, exige observação de sessões, co-terapia, equipamento como salas com vidro espelhado e, desejavelmente, vídeo-tape. Dispõe-se de poucos tapes, os de terapeutas famosos orçam em quantias inacessiveis para a maioria dos psicólogos brasileiros. Disso tudo deduz-se a dificuldade para formação de profissionais na área.

Além dos mais, por ser um trabalho ainda pouco conhecido, poucos são os encaminhamentos de famílias para terapia. Muitas vezes um encaminhamento para terapia individual é caso de terapia familiar, mas essa modificação de tratamento às vezes fica difícil de ser implementada, uma vez que acarreta um custo mais elevado e porque o foco está tão centrado no paciente individual que a família não aceita a mudança.

No que diz respeito ao atendimento à nossa população, este tem-se restringido às famílias de maior poder aquisitivo, devido ao seu elevado custo, uma vez que a duração da sessão é maior e há, na maioria das vezes, necessidade de trabalho em co-terapia. Com isso, a população como um todo fica privada de um atendimento que the traria grandes beneficios.

Essas dificuldades aos poucos vão sendo superadas, à medida em que surgem Sociedades e Institutos congregando profissionais e que pesqui- sas e trabalhos começam a ser publicados. Na medida em que esse tipo de atendimento for se tornando mais conhecido, as Instituições Estatais de Saúde poderão sensibilizar-se para essa modalidade de trabalho, criando condiçōes para um atendimento mais amplo da população, bem como para a formação de profissionais. Deve-se lembrar que o êxito do atendimento familiar no exterior veio em função de sua eficiência efeitos terapêuticos duradouros e diminuição de internaçð̌es (Hoffman p. 259). O trabalho terapêutico com familias é um campo que apresenta inúmeras possibilidades, e, aumentando-se o número de trabalhos, passar-se-á a desenvolver novos modelos, adequados à nossa cultura e população.

\section{REFERENCIAS BIBLIOGRAFICAS}

BATESON, G. Steps to an Ecology of Mind. London, Granada Publishing, 1978.

CARNEIRO, Terezinha F. Família: Diagnóstico e Terapia. Rio de Janeiro, Zahar Ed. 1983.

DELL, P.F. Beyond Homeostasis; Toward a Cohcept of Coherence Family Process, v. 21, p.21-41 s.d

HALDANE, D. and MC CLUSKEY, $v$. Existentialism and Family Therapy: a neglected perspective. Journal of Family Therapy 4: 117-132, 1982.

HOFFMAN, L. Foundations of Family Therapy. New York, Basic Books, 1981.

L'ABBATE, L., FREY J. and WAGNER V. Toward a Classification of Family Therapy Theories: Further Elaboration and Implications of the E-R.A. Awc. C. Model. Family Therapy, v. IX, n. 3, 1982.

MADANES, C. Strategic Family Therapy. San Francisco, Jossey Bass Publ. i981.

MEYER, Luiz Família - Dinâmica e Terapia (Uma Abordagem Psicanalítica). São Paulo, Brasiliense. 1983.

MINUCHIN, S - Familias: Funcionamento e Tratamenio. Trad. J.A. Cunha. Porto Alegre, Ed. Artes Médicas, 1982.

SATIR, V.Terapia do Grupo Familiar. $2^{\text {a }}$ ed. Trad. A. Nolli. Rio de Janeiro, Livraria Francisco Alves, 1980

SLUZKI, C. Process, Structur and World Views: Toward an Integrated View of Sistemic Models in Family Therapy, Family Process, 22: 469-476,1983.

SPECK R. and ATTNEAVE, C. Social Networks as the limit of Intervention, In; GUERIN, P. (ed) Family Therapy: Theory and Practice, New York, Gardner Press, 1976.

WATZLAWICK, P., BEAVIN, J.H JACKSON, D.D. Pragmática da Comunicação Humana, Trad. A. Cabral, São Paulo, Cultrix, 1981.

WEITZMAN, J. Engaging the Severely Dysfunctional Family in Treatment: Basic Considerations. Family Process, v.24, 1985. 